\title{
Integração de habilidades: perspectiva histórico-teórica e operacionalização no exame Celpe-Bras
}

\author{
Maria Gabriela S. Pileggi \\ Universidade Estadual de Campinas (UNICAMP), Campinas, São Paulo, Brasil \\ pileggimg@gmail.com
}

DOI: http://dx.doi.org/10.21165/el.v46i2.1677

\begin{abstract}
Resumo
Este artigo procura traçar uma perspectiva histórico-teórica do tema "integração de habilidades" e como esse é operacionalizado nas tarefas da parte escrita do exame de proficiência Celpe-Bras. Com o surgimento da avaliação de desempenho em língua estrangeira (LE), a integração de habilidades tem sido cada vez mais utilizada. No entanto, o tema ainda é debatido por vários pesquisadores; alguns teóricos apontam para o problema da contaminação de uma habilidade a outra, enquanto outros o defendem por ser mais condizente com abordagens centradas no uso da língua. Dessa forma, busco aqui apresentar o estado da arte da literatura na área de avaliação em LE sobre o conceito "integração de habilidades" e analisar tarefas de produção escrita do exame Celpe-Bras a fim de entender como o conceito tem sido operacionalizado nesse exame.
\end{abstract}

Palavras-chave: avaliação; habilidades integradas; exames de proficiência em língua estrangeira.

\section{Integrated skills: historical and theoretical perspective and operationalization in Celpe-Bras exam}

\begin{abstract}
This article sets a historical and theoretical overview of integrated skills and its operationalization on the Celpe-Bras exam written tasks. With the arrival appearance of performance assessments tests, integrated skills have been increasingly used. However, the theme is still a matter of debate for some researchers. While some theorists raise an issue about a possible skill-to-skill contamination, others defend it as a more language-centered approach. Therefore, the author attempts to present the state-of-the-art literature about 'integrated tasks' and analyses written task from the Celpe-Bras to understand how this theme has been applied in this exam.
\end{abstract}

Keywords: assessment; integrated skills; proficiency tests in foreign language.

\section{Introdução}

Uma das questões pesquisadas na área de avaliação em língua estrangeira é a integração de habilidades (compreensão oral, produção oral, compreensão escrita e produção escrita). Com o advento dos testes de desempenho, que se propõem a avaliar o uso da língua, a integração de habilidades tem sido cada vez mais utilizada.

Entretanto, uma revisão da literatura mostra que o conceito tem sido operacionalizado de maneiras distintas e que há controvérsias em relação ao uso das habilidades integradas. 
Este artigo, um recorte de minha dissertação de mestrado, tem como objetivo mostrar como a literatura tem entendido o conceito e analisar duas tarefas da Parte Escrita do exame Celpe-Bras (Certificado de Proficiência em Língua Portuguesa para Estrangeiros) para entender como essa integração tem sido operacionalizada nesse exame, de forma a contribuir para a melhor compreensão do tema e oferecer contribuições para futuras pesquisas e aprimoramentos dos exames que a utilizam. A metodologia empregada neste trabalho foi qualitativa apoiando-se, sobretudo, na análise documental.

\section{O exame Celpe-Bras}

O crescimento econômico do Brasil no início da década de 1990 e o consequente intercâmbio cultural e econômico com outros países (CARVALHO, 2012) criou a necessidade de uma referência de proficiência em língua portuguesa. Diante disso, em 1993, foi convocada pelo Ministério da Educação (MEC) uma Comissão Técnica, formada por estudiosos na área de Português Língua Estrangeira (doravante, PLE), a fim de elaborar um exame de proficiência em língua portuguesa, pensando principalmente nos candidatos ao Programa de Estudantes-Convênio de Graduação (PEC-G) ${ }^{1}$,

[...] tornava-se necessário propor uma certificação de uso da língua portuguesa para participar da vida na universidade, o que envolveria criar um instrumento de avaliação que aferisse o potencial dos candidatos para ler, escrever, ouvir e falar em interações da vida cotidiana e estudantil. (SCHLATTER, 2014, [n.p.]).

Implementado em 1998, o Celpe-Bras é o único documento brasileiro de proficiência em português como língua estrangeira oficialmente aceito pelo governo brasileiro. No Brasil, é exigido por algumas universidades para ingresso em cursos de graduação e em programas de pós-graduação, além de ser pré-requisito para profissionais estrangeiros de áreas diversas atuarem no país. É requisito obrigatório para alunos dos convênios PEC-G e PEC-PG. Atualmente, é aplicado duas vezes ao ano em 28 postos aplicadores no Brasil e 58 no exterior, em 37 países $^{2}$.

A Parte Escrita do exame é subdividida em quatro tarefas que buscam avaliar a compreensão oral e escrita e a produção escrita de forma integrada. Na Tarefa 1, o examinando assiste a um vídeo e é convidado a produzir um texto escrito a propósito do vídeo. Na Tarefa 2, o examinado ouve um áudio e é convidado a produzir um texto escrito. Já nas Tarefas 3 e 4 o examinando lê um texto fonte e é convidado a produzir um texto dentro de uma situação de comunicação. $\mathrm{Na}$ Parte Oral, com duração aproximada de 20 minutos, o examinando conversa com um examinador (interlocutor) e é avaliado por ele e também por outro examinador (observador) sobre assuntos variados apresentados através dos elementos provocadores, que são pequenos textos e imagens de temas variados que circulam na imprensa escrita brasileira. A integração de habilidades é vista pelos elaboradores do exame como um diferencial:

\footnotetext{
${ }^{1}$ Programa do MEC/MRE que oferece educação superior em universidades brasileiras a cidadãos de países em desenvolvimento que mantêm acordos educacionais e culturais com o Brasil. Mais informações em: <http://www.dce.mre.gov.br/PEC/PECG.php\#tab1>.

${ }^{2}$ Dados disponíveis em: <http://portal.inep.gov.br/web/guest/acoes-internacionais/celpe-bras $>$.
} 
Diferentemente dos exames de proficiência que testam em separado as quatro habilidades (compreensão oral, compreensão escrita, produção oral e produção escrita), o Celpe-Bras avalia esses elementos de forma integrada, ou seja, como ocorrem em situações reais de comunicação. (BRASIL, 2013, p. 5).

O Celpe-Bras certifica quatro níveis de proficiência: Intermediário, Intermediário Superior, Avançado e Avançado Superior através de um único exame. De acordo com o Guia do Participante (2013), a decisão de certificar diferentes níveis através de uma mesma prova "baseia-se na premissa de que examinandos de todos os níveis são capazes de desempenhar ações em língua portuguesa. O que pode variar é a qualidade desse desempenho" (BRASIL, 2013, p. 5). Com isso podemos perceber o construto do exame: avaliar o uso da língua em situações realistas de comunicação. $O$ termo construto ${ }^{3}$ refere-se a um conjunto de denominações construídas que visam referenciar o teste teoricamente.

\section{Perspectiva histórico-teórica da integração de habilidades}

A avaliação de língua estrangeira tem um papel importante na área de Linguística Aplicada, operacionalizando as teorias da área e fornecendo subsídios importantes para que seus pesquisadores façam análises do conhecimento linguístico e do seu uso ${ }^{4}$ (CLAPHAM, 2003). Tendo em vista essa importância, busco mostrar brevemente como a subárea se desenvolveu desde os primeiros testes até os modelos atuais, inserindo, nessa perspectiva histórica, o conceito "integração de habilidades" sob a ótica de estudos diversos, não deixando de considerar as polêmicas e controvérsias que cercam o tema. Considero importante destacar que a base de discussão do tema são os testes em língua inglesa, pois não existem publicações sobre o tema baseadas em testes brasileiros.

\section{A teoria estruturalista}

Spolsky $(1995,2008)$ afirma que foi nos anos de 1960 que a área de avaliação em línguas se desenvolveu como uma área de estudos, com o início da industrialização e centralização dos testes em larga escala produzidos em Princeton e Cambridge. Nessa época, a língua era vista como um conjunto de elementos distintos. De acordo com Lado (1961), a teoria da avaliação de língua concebia a linguagem como um sistema de hábitos de comunicação. Esses hábitos envolveriam questões de forma, sentido e distribuição em vários - e separados - níveis de estrutura, a saber: níveis da oração, da frase $^{5}$, da palavra, do morfema e do fonema. Essa teoria fundamentou o conceito de proficiência da época, bem como o desenvolvimento dos testes.

\footnotetext{
${ }^{3}$ Cf. Ebel e Frisbie (1991).

${ }^{4}$ Citação original: "Language assessment plays a pivotal role in applied linguistics, operationalizing its theories and supplying its researchers with data for their analysis of language knowledge or use" (CLAPHAM, 2000, p. 148).

5 Frase é a menor unidade do discurso capaz de transmitir uma mensagem, oração é um enunciado construído necessariamente em torno de um verbo (ABREU, 2003).
} 
Sob a perspectiva estruturalista, ser proficiente em uma língua pressupunha dominar seus elementos (descritos acimas), isto é, ser proficiente significava "ter conhecimentos sobre a língua e analisá-la em seus vários componentes" (SCARAMUCCI, 2000, p. 15).

Assim, pela separação dos níveis linguísticos (LADO, 1961), pelo conceito de proficiência vigente e pela necessidade de testes confiáveis e práticos, foram desenvolvidos os discrete point tests, ou testes isolados. Nesse tipo de teste, o candidato efetivamente não cria uma resposta nova, mas a escolhe de uma série de opções. Eles podem ser constituídos por questões de verdadeiro ou falso, múltipla escolha ou preenchimento de lacunas, e aceitam apenas uma resposta correta. São chamados de testes isolados por avaliarem os componentes linguísticos de forma isolada $\mathrm{e}$ descontextualizada.

Em oposição às teorias estruturalistas, nos anos 70 surgem os modelos de competência comunicativa, como veremos a seguir.

\section{A abordagem comunicativa e os testes comunicativos}

O termo competência comunicativa foi elaborado por Chomsky em 1965 (SANTOS, 2007). Para Chomsky (apud SANTOS, 2007), a competência linguística baseada num falante nativo ideal, de uma comunidade de fala homogênea que domina a língua perfeitamente - era a capacidade que um falante nativo teria de fazer julgamentos sobre a gramaticalidade das sentenças.

A partir da ideia de competência comunicativa, no final dos anos 70 e início dos 80, a ênfase dos estudos na área de avaliação passou a ser o uso da língua em contexto, e não mais o que ocorria antes, quando o contexto era completamente apagado. Nesse sentido, o conceito de proficiência começou a ser alterado, com mais ênfase em ser proficiente no uso da língua e não apenas na língua.

Nesse período dos anos 80 , os testes passaram por uma mudança significativa, conforme afirma Shohamy (1985 apud ARAÚJO, 2007, p. 37)

A avaliação está, então, deixando para trás a ênfase em habilidades linguísticas separadas, em direção à comunicação prática, que representa a combinação de todas as habilidades. Testes incluem tarefas comunicativas e a avaliação de fatores culturais e sociolinguísticos. As avaliações incluem tarefas reais de comunicação. O aprendiz de línguas deve ser sensível a quem diz o que, para quem, em que momento e de que maneira. A avaliação inclui também adequação, registro e capacidades comunicativas.

Nesse sentido, Brown (2007) afirma que os testes comunicativos devem ser práticos, exigindo que o candidato use a língua dentro de um contexto apropriado e devem medir, em concordância com o apontado acima, uma gama variada de habilidades linguísticas, incluindo conhecimentos sociolinguísticos, de coesão e de funções da língua. 


\section{Os testes de desempenho}

Testes de desempenho (performance test) podem ser definidos, em seu sentido amplo, como um teste em que a capacidade dos candidatos para executar tarefas específicas, geralmente associadas a exigências de trabalho ou estudo, é avaliada (DAVIES et al., 1999 apud WIGGLESWORTH, 2008). Em uma avaliação de desempenho em segunda língua (performance assessment of second language), as tarefas são desenhadas de forma que a habilidade linguística possa ser medida por meio do desempenho, permitindo que os candidatos demonstrem os tipos de habilidades linguísticas que possam ser requeridas em um contexto de 'mundo real' (WIGGLESWORTH, 2008). Nessas tarefas, os candidatos são avaliados numa gama muito maior de habilidades linguísticas do que as tradicionalmente avaliadas nos testes isolados. O que se pretende avaliar no teste de desempenho, então, é a capacidade do avaliando de agir no mundo através da linguagem, "essa capacidade é caracterizada por apresentar um requisito de desempenho que pressupõe o uso integrado de habilidades linguísticas e pragmáticas" (SCARAMUCCI, 2011, p. 107).

Podemos encontrar três fatores principais que distinguem os testes de desempenho dos tradicionais testes de segunda língua: o fato de que existe desempenho pelo candidato, o fato de que este desempenho é julgado com base num conjunto de critérios e as tarefas devem ser as mais autênticas possíveis (MCNAMARA, 1996).

É dentro deste contexto dos testes de desempenho que o conceito integração de habilidades surge e é desenvolvido, como apresentaremos a seguir. Antes de abordar diretamente a integração de habilidades, discutiremos brevemente os conceitos de tarefa, confiabilidade e validade, uma vez que estão diretamente relacionados a testes que envolvam habilidades integradas.

\section{Integração de habilidades: como o conceito surgiu?}

Ao se testarem múltiplas habilidades, faz-se necessária uma distinção entre tarefas integrativas (integrative test tasks) de um lado e tarefas integradas (integrated tests tasks) de outro. Segundo Lewkowicz (1997), para completar uma tarefa integrativa, o examinando precisa empregar simultaneamente mais de uma habilidade linguística. Tarefas do tipo cloze (preencher, com as informações adequadas, lacunas no meio de um texto em que palavras foram apagadas, por exemplo) ou ditado são exemplos de testes integrativos. No teste do tipo cloze, a intenção é testar a língua a partir de um pequeno trecho de texto em que algumas palavras ou expressões foram apagadas; o examinando, então, deve preencher as lacunas com as informações adequadas que foram eliminadas (CHAPELLE; ABRAHAM, 1990). A integração, nesse caso, se opõe à avaliação isolada dos aspectos (níveis da sentença, da oração, da frase, do morfema e do fonema). Nesse tipo de tarefa a proficiência é medida como um todo unitário.

Conforme nos movemos em direção às tarefas integradas, aumentamos o grau de realidade que as tarefas tentam replicar. Um teste com tarefas completamente integradas, ainda de acordo com Lewkowicz (1997), tem que ser baseado no desempenho do candidato, ou seja, tem que ser um teste de desempenho. O pressuposto desse tipo de teste é que a melhor maneira de avaliar a proficiência de uma pessoa é criar condições para que ela possa demonstrar tal proficiência de forma direta em uma 
situação semelhante à realidade (KOBAYASHI, 2010). Assim, uma tarefa integrada dessa natureza tem por objetivo avaliar a proficiência diretamente em um contexto que se aproxime, na medida do possível, do uso da língua na vida real.

Enquanto o ensino experimentava inovações, com o advento da abordagem comunicativa, os testes de língua permaneciam conservadoramente estruturalistas, não sendo capazes de avaliar o que estava sendo ensinado (LEWKOWICZ, 1997). Essa deficiência foi identificada por Morrow (1979), que defendeu a necessidade de incorporar sistematicamente, nos testes, tarefas autênticas definidas dentro de situações comunicativas reais. Ele apontou para a necessidade de se estabelecer um teste dentro de um contexto apropriado aos examinandos, fundamentado em um material com estímulos autênticos e em tarefas que simulassem situações com as quais o examinando poderia deparar-se no mundo real (LEWKOWICZ, op. cit.).

Além da constatação de Morrow (1979), dois novos desenvolvimentos ocorridos na área de avaliação e ensino de língua nos anos 1970 tiveram impacto na elaboração de testes, encorajando uma maior integração. O primeiro foi o trabalho de Munby (1978) em análise de necessidades que levou a uma identificação das exigências linguísticas de grupos específicos de aprendizes. Esse trabalho foi usado como base para a criação de programas de ensino (como, por exemplo, Communicative Syllabus Design) o que nos conduz ao segundo desenvolvimento: o aumento dos cursos de inglês para fins específicos (English for Specific Purposes - ESP). Desse modo, foi criada uma ligação entre os testes e as habilidades previstas como pré-requisitos para o futuro desempenho dos candidatos. Podemos perceber, já nessa época, um início de preocupação em avaliar o desempenho em situações futuras, o que pode ser considerado um embrião do conceito de proficiência proposto por Scaramucci (2000), no qual a proficiência é entendida como um conceito relativo que dependeria das especificidades das situações de uso futuro da língua.

Um dos testes considerados totalmente integrado (ARAÚJO, 2007; LEWKOWICZ, 1997) é a versão pré-1995 do IELTS (International English Language Testing System). Nessa versão, a tarefa principal consistia na produção de um ensaio baseado na leitura de seis trechos retirados de trabalhos acadêmicos, integrando as habilidades de leitura e escrita. A tarefa pretendia replicar o tipo de tarefas que os alunos teriam que desenvolver em seus estudos acadêmicos e a quantidade de leitura obrigatória era, portanto, intencionalmente pesada. Além disso, uma ou duas das passagens de leitura, embora com base em assunto relacionado, não eram relevantes para o cumprimento da tarefa, de modo que, entre outras habilidades, os examinandos tinham que mostrar a sua capacidade de descartar material indesejado. Um dos pontos advogados em defesa dessa integração no exame era a provisão de insumo escrito que garantia que candidatos de contextos culturais diferentes de onde o exame era preparado não tivessem suas capacidades linguísticas subestimadas devido à falta de conhecimento prévio nos assuntos sobre os quais deveriam produzir (ARAÚJO, 2007).

De acordo com Lewkowicz (1997), as vantagens em se utilizar uma abordagem integrada na avaliação de língua incluem o aumento da validade do teste - na medida em que um item integrado fornece uma amostra mais significativa do domínio de LE do examinando do que um item isolado ou integrativo - e a racionalização dos 
procedimentos de avaliação, já que um teste integrado atende a mais de uma finalidade, avaliando mais de uma habilidade ao mesmo tempo.

Outros exames que apresentavam integração de habilidades em suas tarefas foram desenvolvidos no Canadá, em Hong Kong, na Austrália, nos Emirados Árabes Unidos e no final da década de 1990 nos Estados Unidos, com o desenvolvimento do novo TOEFL.

\section{Controvérsias}

Paralelamente ao desenvolvimento das tarefas integradas, também surgiram questionamentos a esses tipos de tarefas no que diz respeito à complexidade das tarefas, contaminação na avaliação, dificuldade em estabelecer níveis de desempenho, validade, entre outros.

Uma das questões levantadas que colocam em dúvida as tarefas integradas é a validade dessas avaliações (GEBRIL; PLAKANS, 2009), pois é necessário compreender melhor as inferências feitas sobre as notas atribuídas às tarefas integradas no que diz respeito, por exemplo, à capacidade de escrita ou à leitura, ou seja, quais inferências sobre a leitura do candidato podem ser feitas a partir da nota atribuída para a produção escrita.

Ainda quanto à questão da validade, Lewkowicz (1997) considera que uma abordagem integrada pode aumentar a validade de um teste, uma vez que os resultados desse tipo de tarefa podem ser interpretados e usados para mais de uma finalidade, pois avalia múltiplas habilidades do examinando em desempenhar-se em situações de uso da língua.

Podemos ver que o assunto não é desprovido de polêmica e ela continua aparecendo sempre que o tema "integrar habilidades" é objeto de pesquisas. No ano de 2013, o periódico Language Assessment Quartely publicou um volume especial sobre o tema, especificamente sobre tarefas integradas de escrita. No artigo introdutório da publicação, Cumming $(2013$, p. 1) levanta cinco perigos ou riscos a que este tipo de tarefa pode estar vulnerável:

(a) confusão na avaliação da habilidade de escrita com a avaliação da habilidade de compreensão dos textos fonte (b) avaliação contaminada para a informação de diagnóstico; (c) envolve gêneros que são mal definidos e difíceis de pontuar; (d) exige limites entre os níveis de habilidade, produzindo resultados do teste que não podem ser nitidamente comparados através dos diferentes níveis de habilidade (e) induz a produção de textos nos quais é difícil distinguir a produção dos examinandos do textofonte.

A contaminação na avaliação é um aspecto citado por vários autores quando se trata de criticar tarefas integradas. O primeiro autor a levantá-lo foi Weir (1990), que cunhou o termo muddied measurement (contaminação na avaliação), usado, como podemos ver na citação acima, até os dias hoje. O autor levanta a hipótese de que seria difícil determinar de forma acurada os pontos fracos e fortes do examinando. Examinar a compreensão em leitura através da escrita, por exemplo, poderia revelar-se uma medida enviesada, "contaminada", ou seja, a deficiência na produção escrita poderia 
prejudicar a avaliação da leitura. O estudo de Sawaki et al. (2013) de certa forma refuta esta teoria, pois conseguiu, até determinado ponto, identificar três construtos correlacionados, mas ainda distintos - leitura, compreensão oral e produção escrita subjacentes nas produções escritas dos examinandos, confirmando a presença das três habilidades.

Nesse sentido, para refutar tanto o item (a), quanto o item (b) e, consequentemente, a hipótese de Weir (1990), Cumming (2013) afirma que esses riscos que uma tarefa integrada de escrita poderia correr só fariam sentido se a escrita fosse vista como uma habilidade independente, totalmente separada das habilidades de leitura ou de compreensão oral. Essa separação é vista por Alderson (2000) como uma distorção inautêntica que enviesaria a avaliação, já que não é possível separar a leitura ou a escrita de seus usos na vida real, ou seja, a leitura em uso é feita através da ativação das outras macro-habilidades, não se dá de forma isolada.

Outra crítica que é feita à integração de habilidades, com menos ênfase, é a questão da tentativa de as tarefas se aproximarem da língua em uso na vida real. A alegação é que o simples ato da avaliação altera a natureza sociocultural do evento, pois quando lemos na "vida real" não estamos sendo avaliados. Assim, o examinando, sabendo que está sendo avaliado, participaria de um evento diferente, dificultando a extrapolação do desempenho no evento avaliativo para o desempenho fora da situação de teste. Alderson (2000) refuta tal crítica argumentando que a habilidade de extrapolação da avaliação para o mundo real é ainda importante, mas é igualmente importante não confundir o evento avaliativo com a 'coisa real'. Conforme já vimos, a integração de habilidades se insere no contexto da avaliação de desempenho, e esse tipo de avaliação pressupõe tarefas que representam situações que possam ocorrer no mundo real. No entanto, Scaramucci (2011, p. 107) afirma que "apesar de realistas, entretanto, as situações de avaliação não serão reais, mas sempre situações de avaliação, que somente poderão ser consideradas reais pelo fato de ocorrerem na vida real", descontruindo, dessa forma, a crítica.

Já em 1986, Emmings (apud LEWKOWICZ, 1997) apontava que uma tarefa integrada poderia reduzir a confiabilidade de um teste, uma vez que uma dificuldade comum com itens integrados escritos é tornar a correção confiável (WEIR, 2005). Brown e Bailey (1984) ressaltam a necessidade de especificações cuidadosas e específicas no tocante à grade de correção de um teste. Nesse sentido, Weir (2005) sugere alguns procedimentos a serem realizados antes da correção, considerando necessário, primeiramente, organizar os principais pontos contidos no texto-fonte, depois construir um esquema de correção e, por fim, padronizar os corretores por meio de critérios explícitos.

Apesar de existirem questionamentos quanto à integração de habilidades operacionalizada em tarefas integradas, a maioria deles pode ser contornada ou evitada se houver um planejamento cuidadoso em todas as etapas do teste. Outros, como a questão da validade, da confiabilidade e da avaliação da habilidade de leitura, ainda precisam de mais estudos antes de tomar essas questões como impeditivas do uso de tarefas integradas. 


\section{Operacionalização da integração de habilidades}

Nessa seção, analiso duas tarefas do ano de 2014, edições 1 e 2, do exame Celpe-Bras. A presente seção está organizada da seguinte forma: reprodução da tarefa original do exame, descrição e análise da tarefa. A seguir, reproduzo a tarefa 3 da edição 2014/1 do exame Celpe-Bras:

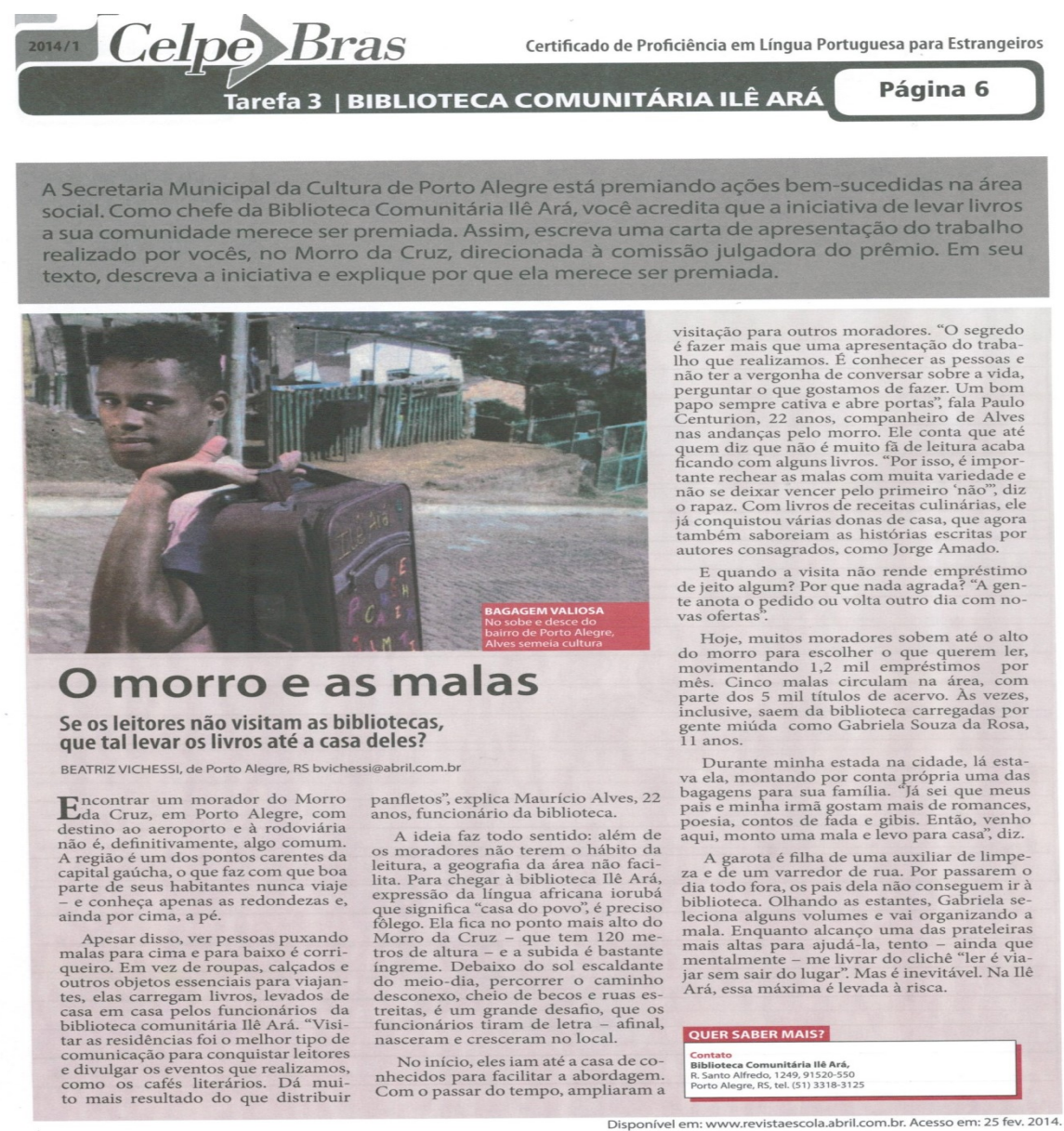

Figura 1. Tarefa 3 da edição 2014/1 de exame Celpe-Bras

Fonte: BRASIL (2014a)

Com o título "Biblioteca comunitária Ilê Ará", a tarefa 3 da primeira edição de 2014 do exame Celpe-Bras traz, como insumo para a produção do examinando, a reportagem do site da Revista Escola intitulada "O morro e as malas". Essa tarefa integra leitura e produção escrita.

Na primeira parte do enunciado, temos a contextualização da tarefa:

(1) A Secretaria Municipal de Cultura de Porto Alegre está premiando ações bem-sucedidas na área social.

A partir desse ponto, são delimitadas as condições de produção da tarefa: o enunciado convida o examinando a se colocar na posição enunciativa de chefe da Biblioteca Comunitária Ilê Ará. A seguir, o enunciado solicita que o examinando escreva uma carta de apresentação do trabalho realizado na comunidade, configurando o 
gênero do discurso a ser produzido, que deve ser direcionada à comissão julgadora do prêmio, logo, o interlocutor da carta de apresentação. Por fim, o enunciado traz o propósito da tarefa: apresentar a iniciativa e explicar por que ela merece ser premiada.

Da forma como o enunciado foi construído, percebemos a tentativa de aproximação da tarefa com uma situação realista de uso da língua. Uma vez que primeiro é apresentado o prêmio oferecido pela Secretaria Municipal de Porto Alegre, depois o enunciador aparece naturalmente inserido - "como chefe da biblioteca" - e é estabelecida, através da extensão da caracterização do enunciador, uma relação entre o enunciador e o prêmio. Com essa relação estabelecida, a solicitação da produção da carta parece ser o passo evidente que o enunciador tomaria, ou seja, se o enunciador acredita que sua iniciativa merece ganhar o prêmio, naturalmente ele escreveria uma carta à comissão julgadora apresentando seu trabalho. Até mesmo a configuração do propósito, descrita no parágrafo anterior, é condizente com as condições de produção apresentadas pela tarefa.

Pelos fatores apresentados, a autenticidade situacional dessa tarefa é alta, uma vez que conseguimos estabelecer um grau alto de correspondência entre a tarefa inserida no contexto avaliativo e a, possível, tarefa de uso real da língua alvo, ou seja, a situação de comunicação proposta pelo enunciado poderia ocorrer em uma situação real de comunicação fora do contexto avaliativo. No entanto, o texto-fonte ficou fora da situação de comunicação. Uma maneira de encaixá-lo seria sua inserção no enunciado, por exemplo:

A Secretaria Municipal de Cultura de Porto Alegre está premiando ações bemsucedidas na área social. Motivado pela publicação da matéria abaixo, como chefe da Biblioteca Comunitária Ilê Ará, você acredita que a iniciativa de levar livros a sua comunidade merece ser premiada. Assim, escreva uma carta de apresentação do trabalho realizado por vocês direcionada à comissão julgadora do prêmio. Em seu texto, descreva a iniciativa e explique por que ela merece ser premiada.

O exposto no parágrafo anterior revela-nos, também, que o enunciado é coerente com o construto do exame, pois avalia a proficiência do examinando através de uso da língua em uma situação de comunicação.

Retomando o propósito da tarefa, para que o examinando o cumpra, ele precisa localizar e entender, através da leitura, informações específicas no texto-fonte, decidir quais informações são relevantes tanto para apresentar a iniciativa quanto para justificar o merecimento do prêmio, reelaborar essas e outras informações e expressar seu ponto de vista quanto ao trabalho feito na comunidade, além de construir uma argumentação de forma a convencer a comissão julgadora do merecimento do prêmio. Através dessas operações que o examinando deve realizar, percebemos a necessidade da leitura do texto-fonte, visto que as informações selecionadas e reescritas são fruto da habilidade de leitura e, no caso da reescrita, da integração da leitura com a produção escrita.

Ainda, uma questão a ser pensada nessa tarefa é se o examinando conseguiria cumprir o propósito recorrendo à cópia de trechos do texto-fonte - questão apontada pela literatura como uma das possíveis limitações das tarefas integradas. Acreditamos que isso seria possível, visto que algumas informações do texto-fonte, se copiadas, poderiam servir para apresentar a iniciativa, como: 
(2) Visitar as residências foi o melhor tipo de comunicação para conquistar leitores.

(3) Cinco malas circulam na área, com parte dos 5 mil títulos do acervo.

E outras poderiam ser copiadas para justificar o merecimento do prêmio, como:

(4) Dá muito mais resultado do que distribuir panfletos.

(5) até quem diz que não é muito fã de leitura acaba ficando com alguns livros

É evidente que apenas a cópia não seria suficiente para a construção de um texto avaliado no nível Avançado Superior, por exemplo, mas um examinando que conseguisse articular minimamente os trechos copiados poderia cumprir o propósito da tarefa e alcançar o nível Intermediário ou até Intermediário Superior. O problema não é apenas se a cópia está presente, mas como ela é articulada com as demais informações do texto do examinando.

Na sequência, reproduzo a Tarefa 3 da edição 2014/2 do exame Celpe-Bras:
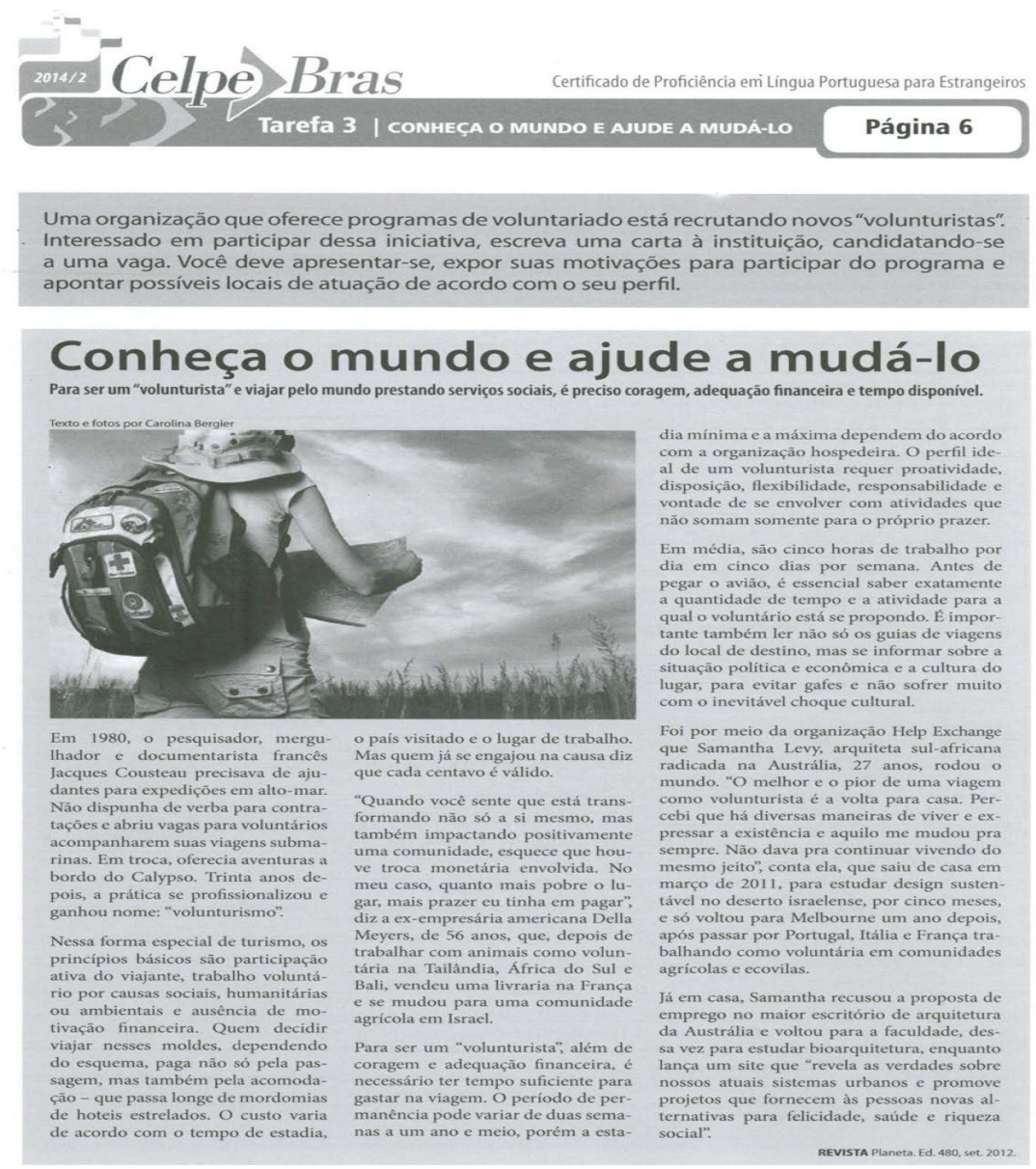

Figura 2. Tarefa 3 da dição 2014/2 do exame Celpe-Bras Fonte: BRASIL (2014b) 
A tarefa 3 da edição de 2014/2, intitulada "Conheça o mundo e ajude a mudálo", tem como insumo para a produção do examinando uma matéria publicada na Revista Planeta sobre programas de voluntariado que aliam turismo e trabalho voluntário.

O enunciado da tarefa começa apresentando ao examinando a informação sobre o recrutamento de "volunturistas". O termo, desconhecido até para falantes de português, pode ser compreendido através do título da matéria, ou seja, "conhecer o mundo" significa fazer turismo e "ajudar a mudá-lo" remete ao trabalho voluntário. Além disso, o examinando pode encontrar uma explicação do termo no lead da matéria. Para chegar a essas conclusões, o examinando precisa localizar e entender informações específicas do texto-fonte, no entanto, ele não precisa ler o texto completo para isso.

A seguir, o enunciado solicita que o examinando se coloque na posição enunciativa de interessado em participar da iniciativa do "volunturismo", caracterizando, assim, o enunciador do texto a ser produzido. Na sequência, o examinando é solicitado a escrever

(6) uma carta à instituição, candidatando-se a uma vaga.

Nessa instrução, temos a delimitação do gênero do discurso a ser produzido: carta, bem como do interlocutor: instituição. E do propósito da tarefa: candidatar-se a uma vaga de "volunturista". Para cumprir esse propósito, de acordo com o enunciado, o examinando deveria, em seu texto,

(7) apresentar-se, expor as suas motivações para participar do programa e apontar possíveis locais de atuação de acordo com seu perfil.

Esses três elementos, que constituem o propósito da tarefa, não exigem a leitura do texto-fonte para serem cumpridos. Em primeiro lugar, para apresentar-se, o examinando não precisa das informações do texto-fonte, uma vez que pode escrever sobre si mesmo ou criar um personagem. Em segundo lugar, para expor suas motivações, o examinando pode recorrer a informações do próprio enunciado, do título da tarefa ou do lead da matéria, por exemplo: "sempre quis participar de programa de voluntariado, porque quero mudar o mundo e tenho tempo disponível, tenho dinheiro e vontade de conhecer muitos países, por isso quero participar do programa e ser "volunturista" ou ainda criar suas próprias motivações. Por último, para apontar os possíveis locais de atuação de acordo com seu perfil, o examinando, mais uma vez, não precisa selecionar informações do texto-fonte, já que o perfil pode ter sido criado e os locais de atuação são os mais diversos, não se restringindo aos mencionados no textofonte, que poderiam ser copiados pelo examinando.

Portanto, as sub-habilidades de leitura demandadas pela tarefa são poucas, restringem-se à localização e compreensão de poucas informações específicas da matéria. Como os nomes dos países e a compreensão do lead para a construção do significado de "volunturista" e do perfil do candidato à vaga. Com isso, o examinando consegue cumprir o propósito da tarefa sem demonstrar evidências de uma boa compreensão do texto-fonte. 
Apesar dessa limitação apresentada, podemos considerar que há integração de habilidades, mas que essa integração é mínima, ou bem menor do que aquela exigida em outras tarefas, pois, para produzir seu texto, o examinando precisa, no mínimo, ter compreendido do que trata o termo "volunturista". Nesse caso, portanto, a produção escrita, na maior parte do cumprimento do propósito, é desvinculada da leitura. Retomando o continuum integrativo-integrado proposto por Lewkowicz (1997), podemos dizer que essa tarefa se encontra mais próxima do extremo "integrativo" do que do extremo "integrado", já que o grau de integração apresentado é baixo.

\section{Considerações finais}

Podemos concluir, considerando que o construto do exame Celpe-Bras busca avaliar proficiência no uso da língua em situações realistas de comunicação, através de tarefas que são um convite para interagir com o mundo, que as tarefas analisadas são coerentes com o construto do exame e são facilmente reconhecidas como tarefas integradas, uma vez que os aspectos dessa integração podem ser observados, em níveis diferentes, nos enunciados das duas tarefas analisadas neste trabalho.

Ainda, diante da análise, corroboramos que as tarefas do exame são, de fato, integradas, pois as tarefas integradas caracterizam-se por solicitar que o examinando demonstre seu desempenho em uma situação de comunicação de uso da língua, que se aproxime ao máximo de uma situação do 'mundo real', através da mobilização de mais de uma habilidade. No caso das tarefas analisadas, temos a mobilização de duas habilidades: leitura e produção escrita.

Com isso, podemos afirmar que integrar as habilidades numa tarefa que se aproxime do mundo real, ou seja, numa tarefa realista pode ser uma das melhores abordagens para se avaliar a proficiência. Podemos afirmar isso tendo em vista as vantagens oferecidas por esse tipo de tarefa: (a) fornecem aos examinandos múltiplos meios de demonstrar sua proficiência em diferentes habilidades, uma vez que, sendo as habilidades requeridas de forma integrada, o examinando tem a oportunidade de mobilizar mais que uma habilidade para realizar a tarefa; (b) aumentam o efeito retroativo do teste nas práticas de ensino e aprendizagem na área de português língua estrangeira/segunda língua; visto que as tarefas integradas replicam o uso da língua em situações realistas de comunicação, essa prática pode servir para que o ensino deixe de ser estruturalista e, por fim, (c) aumentam a autenticidade dos testes promovendo situações de comunicação com as quais os examinandos podem se deparar no uso da língua fora do teste.

\section{REFERÊNCIAS}

ABREU, A. S. Gramática mínima: para o domínio da língua padrão. 2. ed. Cotia: Ateliê Editorial, 2006.

ALDERSON, J. C. Assessing Reading. Cambridge: Cambridge University Press, 2000. (Cambridge Language Assessment). Disponível em: $<$ http://dx.doi.org/10.1017/CBO9780511732935>. Acesso em: 28 mai. 2014. 
ARAÚJO, K. S. A perspectiva do examinando sobre a autenticidade de avaliações em leitura em língua estrangeira. 2007. 147 f. Dissertação (Mestrado em Linguística Aplicada) - Instituto de Estudos da Linguagem, Universidade Estadual de Campinas, Campinas. Disponível em: <http://libdigi.unicamp.br/document/?code=vtls000430295>. Acesso em: 25 jul. 2014.

BRASIL. Ministério da Educação. Guia do participante: tarefas comentadas que compõem a edição de abril de 2013 do exame. 2013. Disponível em: $<$ http://download.inep.gov.br/outras_acoes/celpe_bras/estrutura_exame/2014/guia_parti cipante_celpebras_caderno_provas_comentadas.pdf $>$. Acesso em: 08 abr. 2014.

BROWN, H. D. Principles of language learning and teaching. 5th ed. White Plains: Pearson/Longman, 2007.

BROWN, H. D.; BAILEY, K. M. A categorical instrument for scoring second language writing skills. Language Learning, Hoboken, v. 34, n. 4, p. 21-38, 1984. Disponível em $<$ http://onlinelibrary.wiley.com/doi/10.1111/j.1467-1770.1984.tb00350.x/full $>$. Acesso em: 20 jul. 2015.

CARVALHO, S. C. Políticas de promoção internacional da língua portuguesa: ações na América latina. Trab. linguist. apl., Campinas, v. 51, n. 2, p. 459-484, 2012. Disponível em: <http://dx.doi.org/10.1590/S0103-18132012000200010>. Acesso em: 20 mai. 2014 .

CHAPELLE, C.; ABRAHAM, R. G. Cloze method: what difference does it make? Language Testing, Londres, v. 7, n. 2, p 121-146, 1990. Disponível em: $<$ http://journals.sagepub.com/doi/abs/10.1177/026553229000700201>. Acesso em: 04 jun. 2015.

CLAPHAM, C. Assessment and Testing. Annual Review of Applied Linguistics, Cambridge, v. 20, n. 1, p. 147-161, ago, 2003. Disponível em: $<$ http://citeseerx.ist.psu.edu/viewdoc/download?doi=10.1.1.455.4548\&rep=rep1\&type= pdf $>$. Acesso em 10 mai. 2014.

CUMMING, A. Assessing Integrated Writing Tasks for Academic Purposes: Promises and Perils. Language Assessment Quarterly, v. 10, n. 1, p. 1-8, 2013. Disponível em: $<\mathrm{http}$ //dx.doi.org/10.1080/15434303.2011.622016>. Acesso em: 11 mar. 2015.

KOBAYASHI, E. Avaliação em língua inglesa em contexto empresarial. Sínteses (UNICAMP. Online), v. 15, p. 92-109, 2010. Disponível em: $<$ http://revistas.iel.unicamp.br/index.php/sinteses/article/view/1153>. Acesso em: 19 mai. 2015.

EBEL, R. L.; FRISBIE, D. A. Essentials of Educational Measurement. 5. ed. Englewood Cliffs, Prentice-Hall, 1991.

GEBRIL, A.; PLAKANS, L. Investigating Source Use, Discourse Features, and Process in Integrated Writing Tests. Spaan Fellow Working Papers in Second/Foreign Language Assessment, Ann Arbor, v. 7, p. 47-84, 2009. Disponível em: $<$ http://www.researchgate.net/publication/237836160_Investigating_source_use_disc ourse_features_and_process_in_integrated_writing_tests $>$. Acesso em: 16 mar. 2015. 
LADO, R. Language testing: the construction and use of foreign language tests. New York: McGraw-Hill, 1961.

LEWKOWICZ, J. A. The integrated testing of a second language. In: CLAPHAM, C.; CORSON, D. (Org.). Encyclopedia of Language and Education, v. 7: Language Testing and Assessment. Dordrercht: Kluwer Academic Publishers, 1997. p. 121-130.

MCNAMARA, T. F. Measuring second language performance. Londres: Longman, 1996.

MORROW, K. Communicative language testing: revolution or evolution? BRUMFIT, C.; JOHNSON, K. (Coaut. de). The communicative approach to language teaching. Oxford: Oxford University Press, 1979. p. 143-157.

MUNBY, J. L. A communicative syllabus design. Cambridge: Cambridge University Press, 1978.

SANTOS, L. G. dos. Avaliação de desempenho para nivelamento de alunos de português como língua estrangeira. 2007. 179 f. Dissertação (Mestrado em Linguística Aplicada) - Instituto de Letras, Universidade Federal do Rio Grande do Sul, Porto Alegre, 2007. Disponível em: <http://hdl.handle.net/10183/12750>. Acesso em: 09 mai. 2014.

SAWAKI, Y.; QUINLAN, T.; YONG-WON, L. Understanding Learner Strengths and Weaknesses: Assessing Performance on an Integrated Writing Task, Language Assessment Quarterly, v. 10, n. 1, p. 73-95, 2013. Disponível em: $<$ http://dx.doi.org/10.1080/15434303.2011.633305>. Acesso em: 14 mar. 2015.

SCARAMUCCI, M. V. R. Proficiência em LE: considerações terminológicas e conceituais. Trabalhos em Linguística Aplicada, Campinas, v. 36, p. 11-22, 2000. Disponível em: <http://dx.doi.org/10.1017/S0267190500200093>. Acesso em: 05 jun. 2015.

. Validade e consequências sociais das avaliações em contextos de ensino de línguas. LINGVARVMARENA, Porto, v. 2, p. 103-120, 2011. Disponível em: $<$ http://ler.letras.up.pt/uploads/ficheiros/9824.pdf>. Acesso em: 25 jun. 2015.

SCHLATTER, M. Celpe-Bras: avaliação, ensino e formação de professores de português como língua adicional. Porto Alegre: Editora da UFRGS, 2014. Disponível em: <http://www.ufrgs.br/acervocelpebras/um-pouco-de-historia>. Acesso em: 21 mai. 2014.

SHOHAMY, E. A Practical Handbook in Language Testing for the Second Language Teacher. Tel-Aviv University: Tel-Aviv. Experimental Edition, 1985.

SHOHAMY, E.; HOMBERGER, N. H. (Ed.). Encyclopedia of Language and Education, 2nd Edition, Volume 7: Language Testing and Assessment, New York: Springer Science + Business Media LLC, 2008. p. 445-454.

SPOLSKY, B. Measured words: the development of objective language testing. Oxford: Oxford University Press, 1995. (Oxford applied linguistics). 
Language Assessment in Historical and Future Perspective. In: SHOHAMY, E.; HOMBERGER, N. H. (Ed.). Encyclopedia of Language and Education, 2nd Edition, Volume 7: Language Testing and Assessment, New York: Springer Science+Business Media LLC, 2008. p. 445-454.

WEIGLE, S. C. Assessing Writing. Cambridge: Cambridge University Press, 2002. Disponível em: < http://dx.doi.org/10.1017/CBO9780511732997>. Acesso em: 12 nov. 2013

WEIR, C. J. Communicative Language Testing. Londres: Prentice Hall International (UK) Ltd, 1990.

WEIR, C. J. Language testing and validation: an evidence-based approach. Hampshire: Palgrave Macmillan, 2005.

WIGGLESWORTH, G. A. Task and performance based assessment. In: HORNBERGER, N. H. Encyclopedia of Language and Education. Boston, MA: Springer Science + Business Media LLC, 2008. p. 3-17. Disponível em: $<$ http://dx.doi.org/10.1007/978-0-387-30424-3>. Acesso em: 1 abr. 2014.

Recebido em: 30/08/2016

Aprovado em: 03/02/2017 